in text-books. She found that the incubation period lengthens as the temperature decreases, that below $50^{\circ} \mathrm{F}$. no incubation takes place, and that oothecæ submitted to this low temperature do not incubate if later exposed to more favourable temperatures. This was suggested as a partial explanation of the failure of the species to become widely established in Great Britain. Miss Bunting is a pupil of Thorne Grammar School, near Doncaster.

Keith I. Watson (Charterhouse) described "The Charterhouse Astronomical Project", the chief object of which was to revive within the school an astronomical society, first conceived when an observatory was added to the science laboratories in 1907. A retired master, Mr. R. C. Sclater, set up an observatory in his garden and made it a practice to invite parties of boys to make use of his telescope at week-ends. Unfortunately, he soon died and the project collapsed, to be revived again about four years later, in 1936. The organizers decreed that only sixth-form boys could become members---a rule that has now been wisely abandoned on the grounds that in order to maintain continuity with a changing schoolpopulation it is necessary to encourage the younger boys to take part. The work had to be suspended when war broke out and the observatory was used as a fire-watching post.

The present project was commenced in 1953 through the influence of a physics master, $\mathrm{Mr}$. Hayward, and has been encouraged and assisted by a local medical practitioner, Dr. Lyne-Pirkis. To use Keith Watson's own words, "on a clear evening we are at liberty to telephone him and he picks us up in his car and takes us to his observatory where we always spend a very pleasant and instructive evening".

The work planned for the society is determined by the equipment available. The mirror of its original 61 -in. reflecting telescope has been damaged, and since they cannot afford to pay for it to be repaired professionally the members intend to grind a new mirror for themselves. They now have also a 3 -in. Cooke refractor, which, being simpler to use, is more popular.

Some of the boys are mapping portions of the Moon's surface, paying special attention to regions on the edge of the disk that, being difficult to observe and in many cases not very interesting, tend to be neglected by most astronomers. The main task of the solar section has been to plot the course and cycles of sunspots.
The society has about fifty members, but as with most local societies only a few are really active, the others being what Keith Watson aptly described as satellites, attending lectures but doing little practical work. It is interesting to record that a paper embodying observations on "Bee-eaters in Britain" was read by another Charterhouse boy, James J. Swift, at another session of the Section.

The last paper was on "The Ecology of Porter Brook", by John K. Chesters (High Storrs Grammar School, Sheffield). It was a description of work done on the headstream of the River Porter, which runs off the moors on the west side of Sheffield.

Animals were collected in a Surber net, the horizontal frame of which marked out one square foot of the bottom surface. The net faced upstream and collected all the animals loosened from the rocks and the bottom debris. The contents of the net were washed into jars and afterwards sorted, counted and identified.

A chart was prepared expressing the results of the count in terms of the distance in feet from the source of the brook and the months in which the samples were taken. This revealed interesting variations in the number and relative importance of several stonefly nymphs and chironomid larvæe in various parts of the brook and at various times of the year, and showed that annelid worms were found in large numbers near the source of the stream but not elsewhere.

As one of several examples of the results obtained, it was pointed out that the numbers of chironomid larvæ increased greatly (in April and May) at the junction of the Porter Brook with another small stream, the Mayfield. Since the larvæ live in the bottom organic debris and are liable to be swept away by fast bottom currents it was thought that their greater abundance in the combined stream was due to there being a relatively slower bottom current in the somewhat deeper water. Tests showed that on similar bottoms the bottom velocity above the junction was twice as great as below it.

The general conclusions arrived at were that the main factors affecting life in the stream during winter and early spring were the velocity and volume of the water, but that during the remainder of the year there were complications due to other factors such as the amount of vegetation overgrowing the stream and controlling not only the supply of higher plant material but also the intensity of illumination.

F. J. NORTH

\title{
OBITUARIES
}

\section{Dr. G. J. H. Swoboda}

Gustave Swoboda, who died at Geneva on September 4, aged sixty-three, was widely known to meteorologists as the administrative head of the pre-war International Meteorological Organization and its successor, the World Meteorological Organization. Swoboda was a Czech (he later acquired Swiss nationality), a native of Prague, where he graduated in 1920 with the degree of Ph.D. In the same year he joined the State Meteorological Institute and ultimately became chief of the forecasting service. During this period he lectured on meteorology at the technical college in Prague and wrote a technical treatise on aeronautical meteorology. He was one of the first meteorologists outside Norway to give wholehearted support to the ideas of the Bjerknes school, and among other works he collaborated with ' '. Bergeron in a memorable essay on waves and vortices on a quasi-stationary surface.

The turning point in Swoboda's career came when he was appointed a member of the International Meteorological Organization's Commissions for Synoptic Weather Information and for Aeronautical Meteorology. The International Meteorological Organization was a non-governmental body, super- 
vized by a conference of directors of various national services. Swoboda had, apart from his meteorological knowledge, one great asset for such international work. He was a very accomplished linguist, who spoke Czech and German as mother tongues, English and French with complete ease and had considerable knowledge of Dutch and several other European languages. It was therefore no surprise that in 1938 he was selected to succeed Dr. Cannegieter as chief of the secretariat of the Organization, and it was he who supervized the transfer of its headquarters from De Bilt to Lausanne.

Swoboda managed to hold the Organization together during the years of the Second World War and gained his reward in 1951 when the World Meteorological Organization, a Specialized Agency of the United Nations and the successor to the International Organization, appointed him as its first secretary-general. This post he held until September 1953 when he reached the normal age of retirement; but he continued to serve in an acting capacity until August 1955. At the time of his death he was professor of meteorology at Istanbul.

Swoboda's work as a scientist was recognized in 1953 when the Royal Netherlands Academy of Sciences awarded him the Buys Ballot Medal ; but his unique contribution to meteorology undoubtedly was in the field of international co-operation. He was, in many ways, the ideal international Civil servant, and his success in this role arose as much from his kindliness and tact as from his linguistic gifts and administrative ability. He had not only a wide knowledge of his subject but also a great charm of manner and a genuine concern for the happiness and welfare of all around him. He leaves a widow and one son.

O. G. Strton

\section{Dr. C. B. Rees}

Colin Bevan Rees died on September 2, a victim of cancer, at the early age of forty-one ; and by his death marine biology has lost an enthusiastic and original plankton worker who was developing important new lines of research. Born at Pontardawe in Glamorgan on October 25, 1914, he was educated at Pontardawe Grammar School and University College, Cardiff. After graduating with first-class honours and making an ecological study of the fauna of the Severn Estuary, he was appointed in 1937 to the research staff of the Department of Zoology and Oceanography at University College, Hull, which was then expanding its plankton recorder survey. Jointly with Mr. K. M. Rae, he produced a report on the distribution of the Copepoda which was noteworthy for its account of the month-by-month advance of Atlantic indicator species into the North Sea from the north.

After war service as a captain in R.E.M.E., he returned to the plankton recorder team and moved with them to the new Oceanographic Laboratory of the Scottish Marine Biological Association at Edinburgh. He now conclusively demonstrated the reality of the previously disputed two forms of Calanus: finmarchicus and helgolandicus, and studied their distribution and development in different areas of the North Sea. Next he turned his attention to the planktonic larvæ of bottom-living invertebrates. He first set out to devise a method of identification for the multitude of lamellibranch larvæ; by using shape, form of hinge, and texture he distinguished seventy-seven types and produced an account, illustrated with diagrams and photographic plates, which has proved invaluable for other workers. A series of reports followed on the distribution of the larvæ of lamellibranchs, decapod crustaceans, echinoderms and other benthic animals. His University awarded him the D.Sc. in 1951. During his illness he made the final corrections to a further study of the two forms of Calanus, this time comparing their population production in the Atlantic and the North Sea over different seasons. He leaves a mass of data on the other copepod species which it is hoped may be prepared for publication later.

Colin Rees will be remembered by his colleagues and many friends for his devotion to research and for his cheerful good company. He was artistic and, as a hobby, painted in water-colour with distinction, exhibiting in leading Scottish galleries. Our sympathy goes to his widow and two children.

A. C. Hardy

\section{NEWS and VIEWS}

\section{Brazilian Society for the Progress of Science}

The annual meeting of the Brazilian Society for the Progress of Science was held this year during July $2-7$ in the old gold-mining centre of Ouro Preto. The president of the Society, whose term of office runs for two years, is Dr. Anisio Teixeira, the distinguished Brazilian educationist, and the inaugural lecture was given by Prof Carlos Chagas, the president for the meeting, on "Prospects and Problems of Scientific Research in Brazil". The subjects discussed at the meeting, which was attended by about two hundred Brazilian scientists, were divided into nineteen sections. The largest number of papers were presented in the four sections devoted to physiology (including biophysics, biochemistry and pharmacology); physics (and astronomy); microbiology (including epidemiology and preventive medicine); and chemistry. Papers on biological and medical subjects accounted for 65 per cent of the total of 211 papers presented. Foreign guests included Prof.
A. M. Monnier, neuro-physiologist, Prof. J. L'Héritier, geneticist, both of the Collège de France, Prof. J. A. D. Cooper, biophysicist, of the University of Chicago, and Mr. F. M. Beatty, science officer of the British Council in Brazil, who lectured on the training of scientists and technologists in British universities. The next annual meeting of the Society will be held in Rio de Janeiro during July 1957; the 1958 meeting, celebrating the first decade of the Society's existence, will be more international and will prob. ably be held in São Paulo.

\section{Electronic Equipment working at Red Heat}

A DEmonstratron has recently been given at the Research Laboratory of the General Electric Company, Schenectady, N.Y., of electronic components and devices working at temperatures of red heat and, in some cases, under the action of intense nuclear radiation in an atomic reactor. Conventional electronic equipment usually breaks down at $200^{\circ} \mathrm{F}$. or 